\title{
Triple-shape memory effect in 3D-printed polymers
}

\author{
L. Dai ${ }^{1}, J$. Song $^{2}$, S. $Q u^{2}$, R. Xiao ${ }^{2 *}$ \\ ${ }^{1}$ School of Civil Engineering and Architecture, Zhejiang Sci-Tech University, Hangzhou, 310018 Zhejiang, China \\ ${ }^{2}$ Key Laboratory of soft Machines and Smart Devices of Zhejiang Province, Department of Engineering Mechanics, \\ Zhejiang University, Hangzhou, 310027 Zhejiang, China
}

Received 29 December 2019; accepted in revised form 21 May 2020

\begin{abstract}
A triple-shape memory effect represents that polymers can memorize two temporary shapes and show a subsequent recovery from the second temporary shape to the first temporary shape and further to the permanent shape with heating, which provides more design freedom for the applications of shape-memory polymers. In this work, we investigate the shapememory performance of three polymers produced by a commercial 3D printer. Two polymers with a pure component exhibit distinct glass transition regions spanning $30^{\circ} \mathrm{C}$ for each material. The copolymer has a broader glass transition region from -4 to $59^{\circ} \mathrm{C}$. The dual-shape memory tests show that the deformation temperature has a limited influence on the two pure polymers, while a clear temperature memory effect can be observed in the copolymer. For the copolymer, the recovery region has only a small overlap when deformed at 60 and $20^{\circ} \mathrm{C}$, which allows programming two temporary shapes at these two temperatures. Both uniaxial tension tests and three-dimensional demonstration show that the copolymer exhibits a good triple-shape memory effect.
\end{abstract}

Keywords: smart polymers, shape-memory polymers, triple-shape memory effect, $3 D$ printing

\section{Introduction}

The conventional shape-memory polymers (SMPs), which can only return to the permanent shape in each shape memory cycle, display the so-called dualshape memory effect [1-6]. In contrast, the triple SMPs can fix two temporary shapes and recover sequentially from one temporary shape to the other and eventually to the permanent shape with increasing temperature [7-9]. The triple/multiple-shape memory effect, together with the two-way shape memory effect, has enabled SMPs to perform more functionality, which has potential applications in various areas, such as sensors and self-deployed structures [10-12].

Several strategies have been proposed to achieve the triple-shape memory effect in polymers. Luo and Mather [7] fabricated shape-memory composites, consisting of a SMP matrix with a high glass transition region and non-woven fibers with a low melting transition region. Chen et al. [13] synthesized crosslinked liquid crystalline networks exhibiting a glass transition and a nematic-isotropic phase transition. Hoeher et al. [14] achieved the triple-shape memory effect by chemical crosslinking a blend of polyethylene with distinctly different melting temperatures. Hoeher et al. [15] further adopted polymorphism of syndiotactic polypropylene to design a triple-SMP, which is sensitive to the heating rate applied for triggering. Some works $[16,17]$ have employed the coextrusion to create multilayer structures composed of two or more components, each of which exhibits a distinct melting or glass transition region. The physical mechanism of achieving the triple-shape memory effects in the above material and structure systems is that two-phase transitions exist, and each phase transition can be used to fix one temporary 
shape [18-21]. In contrast, polymers with a broad glass/melting transition region can also demonstrate a good triple-shape memory behavior [8, 22]. This is because SMPs show a temperature memory effect, which means the recovery region is directly related to the deformation temperatures. Thus, for a broad glass/ melting transition region, the polymers can be programmed to two temporary shapes with separated recovery regions. Xie [23] firstly demonstrated that Nafion, with a broad glass transition region from 55 to $130^{\circ} \mathrm{C}$, can memorize two and more temporary shapes. A comprehensive review of the triple/multishape memory effects in polymers can be found in Xiao et al. [24] and Wang et al. [25].

Though various triple SMPs have been reported, the material syntheses still mainly base on the traditional curing and extrusion methods, which have intrinsic difficulty in fabricating structures with complex geometries to satisfy the requirement of some practical applications. Instead, the fast development of 3D printing technique offers a feasible way to design SMP-based devices with complicated structures [2632]. For example, Lin et al. [30] employed the 3D printing technique to fabricate occlusion devices based on SMPs. A detailed characterization, both in vitro and in vivo, was carried out to obtain the actual performance of this medical device. Zhang et al. [29] integrated the self-healing property into printed SMPs with complex geometries. Different from the commonly used thermoset polymers, Miao et al. [33] printed SMP systems with dynamic bonds resulting in reconfigurability of the permanent shape. The 3D printed structures can further show a time-dependent response to the environmental stimulus, which is named as $4 \mathrm{D}$ printing. Several groups have employed $4 \mathrm{D}$ printing to achieve the triple-shape memory effect and further multiple-shape memory effect [34-36]. In this work, we focus on the triple-shape memory behaviors of printed polymers. We explore the shape memory performance of three polymers, including two pure polymers and one copolymer, which are all printed using a commercial 3D printer. The glass transition region of three polymers is first characterized using a small strain dynamic test. The uniaxial tension test is adopted to investigate the shape memory response. The dual-shape memory tests are carried out on all three polymers, while the triple-shape memory characterization is performed on the copolymer. The triple-shape memory performance of a printed complex structure with multiple components is also investigated.

\section{Experimental methods}

\subsection{Materials}

The materials were printed using a commercial 3D printer Objet260 (Stratasys, Ltd. USA). All the printed polymers are photosensitive resins, including two pure components with commercial names Tango and Vero, and a copolymer resin with a commercial name 2085. The Tango liquid resin is composed of urethane polyurethane resin, acrylate oligomer, exo1,7,7-trimethylbicyclo[2.2.1]hept-2-yl acrylate, methacrylate oligomer, and a photoinitiator. And the Vero liquid resin comprises isobornyl acrylate, acrylic monomer, urethane acrylate, epoxy acrylate, acrylic monomer, acrylic oligomer, and a photoinitiator [37, 38]. The copolymer 2085 is a mixture of Tango and Vero. Before printing, the CAD file for the specially designed geometry was implemented into the 3D printer. During printing, the polymeric inks were preheated to around $65^{\circ} \mathrm{C}$ and jetted from print heads. Ultraviolet light within the printer was used to cure the resin. The specimens were printed at $100 \mu \mathrm{m} / \mathrm{min}$ with a layer thickness set at $30 \mu \mathrm{m}$. Three different types of specimens were printed. To characterize the mechanical properties, film specimens with a dimension of $25 \mathrm{~mm} \times 5 \mathrm{~mm} \times 1 \mathrm{~mm}$ were printed. For the demonstration of the triple-shape memory effect, we also printed film specimens with a dimension of $80 \mathrm{~mm} \times 5 \mathrm{~mm} \times 1 \mathrm{~mm}$. A film specimen with two materials was also printed with the detailed information shown in the results part.

\subsection{Characterization}

Some general mechanical properties of the printed polymer have already been provided by the Stratasys Ltd (https://www.stratasys.com/materials). Here, some extra mechanical tests were carried out to further investigate the mechanical properties and shape memory performance of the three polymers with an emphasis on the copolymer 2085. The following characterization tests were performed on a dynamic mechanical analyzer (DMA) Q800 (TA Instruments, New Castle, DE, USA) with a specimen size of $25 \mathrm{~mm} \times 5 \mathrm{~mm} \times 1 \mathrm{~mm}$. The specimens were first subjected to a dynamic temperature sweep scanning with a dynamic strain of $0.2 \%$ and a frequency of $1 \mathrm{~Hz}$ to obtain the glass transition region. 
The specimens were heated from -50 to $100^{\circ} \mathrm{C}$ at $3{ }^{\circ} \mathrm{C} / \mathrm{min}$.

The stress-strain relationship was obtained in a constant force rate loading condition. Tango specimens were deformed at $-10,0,20$ and $40^{\circ} \mathrm{C}$ respectively. Vero specimens were deformed at 60,80 , and $100^{\circ} \mathrm{C}$, while the specimens of the copolymer 2085 were deformed at $20,40,60$, and $80^{\circ} \mathrm{C}$. The deformation temperature was chosen based on the glass transition region of each material. The stress-strain relationship was further used to investigate the dual-shape memory effect. The loading rate was set as $1 \mathrm{~N} / \mathrm{min}$. The specimens were all stretched to a final engineering strain of around $10 \%$.

The dual-shape memory effects were investigated in the force-control mode of DMA. The specimens were first deformed at a constant force rate for $1 \mathrm{~min}$ at a high temperature, cooled down to a temperature below the glass transition region at $5{ }^{\circ} \mathrm{C} / \mathrm{min}$, and then unloaded to zero force to obtain the temporary shape. The force rate was chosen to obtain an engineering strain of around $10 \%$ during the programming step. The specimens were then heated at $2{ }^{\circ} \mathrm{C} / \mathrm{min}$ to achieve shape recovery in the stress-free state. The effect of programming temperature $\left(T_{\mathrm{p}}\right)$ was also investigated with at least two deformation temperatures for each polymer. Among three polymers, Vero can withstand the smallest deformation. Thus, cyclic tests were also performed on Vero. The experimental setup is the same as the dual-shape memory tests. The total cycles were chosen as 10 . The triple-shape memory performance of the copolymer 2085 was also analyzed. The specimen was first stretched at $0.8 \mathrm{~N} / \mathrm{min}$ for $1 \mathrm{~min}$ at $60^{\circ} \mathrm{C}$, cooled to $20^{\circ} \mathrm{C}$, unloaded to zero force, reloaded again at $3.2 \mathrm{~N} / \mathrm{min}$ for $1 \mathrm{~min}$, cooled to $-20^{\circ} \mathrm{C}$ and unloaded

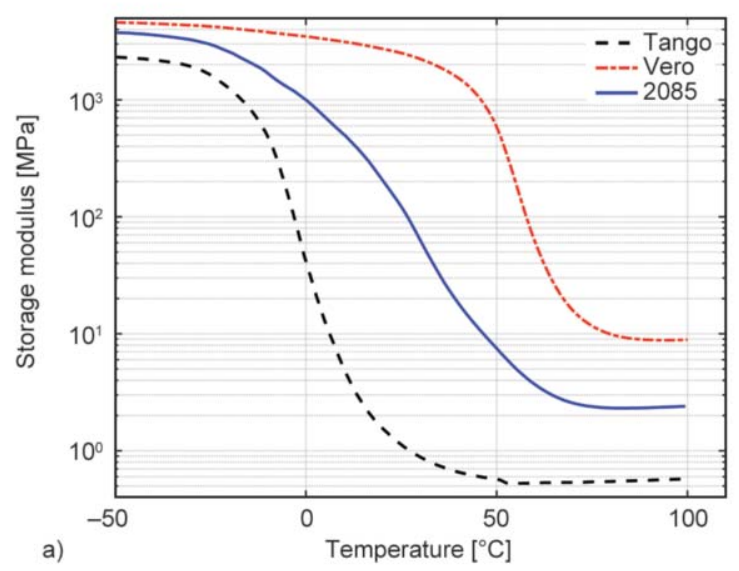

to zero force again. The cooling rate was chosen as $5^{\circ} \mathrm{C} / \mathrm{min}$. During the recovery process, the specimen was first heated to $20^{\circ} \mathrm{C}$, held for 0,15 or $60 \mathrm{~min}$, and then heated to $70^{\circ} \mathrm{C}$. The heating rate was chosen as $2{ }^{\circ} \mathrm{C} / \mathrm{min}$. The $3 \mathrm{D}$ demonstrations were also provided. In the demonstration, the specimens were programmed with the first temporary shape at $60^{\circ} \mathrm{C}$ and cooled to $20^{\circ} \mathrm{C}$, while the second temporary shape was programmed at $20^{\circ} \mathrm{C}$ and cooled to $-10^{\circ} \mathrm{C}$. The two recovery temperatures were chosen as 20 and $60^{\circ} \mathrm{C}$, respectively. The shape programming and recovery were achieved in water with different temperatures, while the condition of $-10^{\circ} \mathrm{C}$ was reached using freezing saltwater.

To characterize the glass transition behavior of the copolymer, a differential scanning calorimetric (DSC) scanning was also performed on a differential scanning calorimeter DSC 25 (TA Instruments, USA). A specimen with a weight of $10 \mathrm{mg}$ was heated from -50 to $90^{\circ} \mathrm{C}$ at $10^{\circ} \mathrm{C} / \mathrm{min}$.

\section{Results}

Figure 1 compares the responses of the three polymers from the dynamic mechanical analysis. As shown, the glass transition of the two pure components is well separated, while the glass transition region of the copolymer 2085 is between that of Tango and Vero. The peak of $\tan \delta$ of the copolymer is the smallest among three polymers. In the glass transition region, the storage modulus quickly decreases by $2-3$ orders. In contrast, in the rubbery region, the storage modulus increases with temperature for all three polymers due to entropic hyperelasticity.

To quantitatively evaluate the glass transition behaviors, we define the low and high glass transition temperatures $\left(T_{\mathrm{g}}^{\mathrm{l}}\right.$ and $\left.T_{\mathrm{g}}^{\mathrm{h}}\right)$ from the intersections between

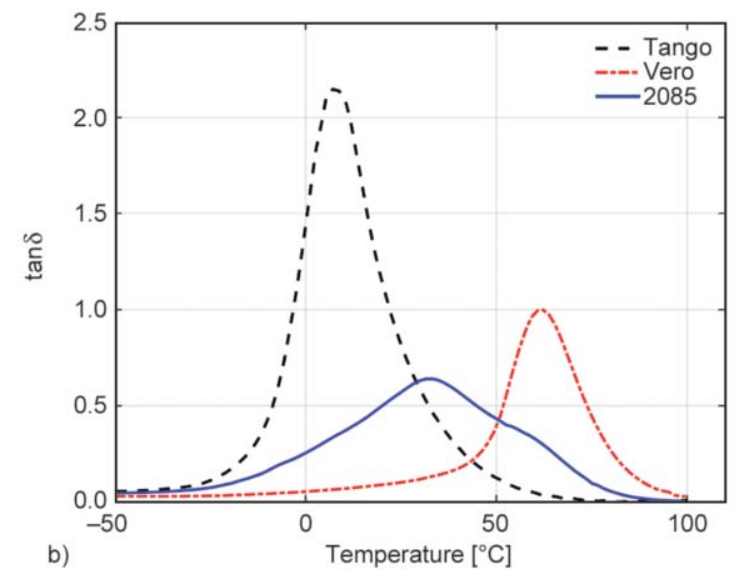

Figure 1. a) Storage modulus and b) $\tan \delta$ as a function of temperature of three polymers. 


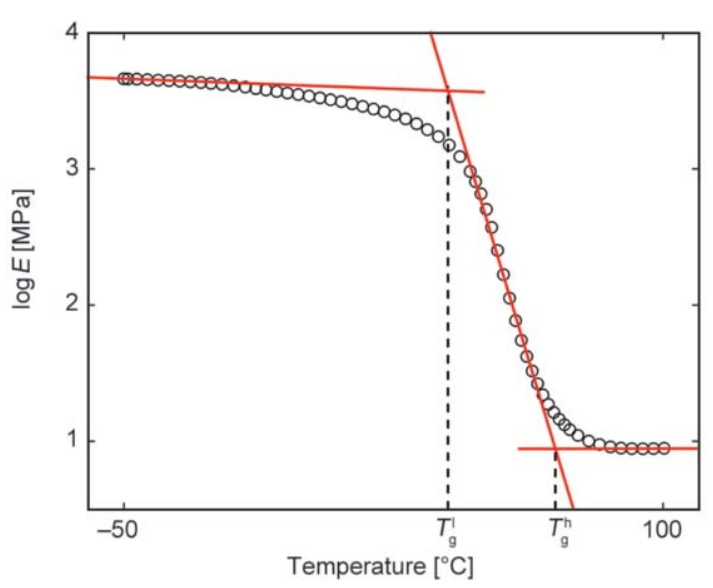

Figure 2. An illustration for determining the glass transition temperature from storage modulus.

the lines fit the plateau regions and the transition region, as shown in Figure 2. For each polymer, the fitted region of the glassy plateau was chosen from -50 to $-40^{\circ} \mathrm{C}$, while the fitted region of the rubbery region was set from 90 to $100^{\circ} \mathrm{C}$. For the transition regions, the fitted regions were chosen as $-10-10^{\circ} \mathrm{C}$, $45-65^{\circ} \mathrm{C}$, and $10-40{ }^{\circ} \mathrm{C}$ for Tango, Vero, and the copolymer 2085, respectively.

As shown in Table 1, the breadth of the glass transition region, defined as $\Delta T g=T_{\mathrm{g}}^{\mathrm{l}}-T_{\mathrm{g}}^{\mathrm{h}}$, is around $30^{\circ} \mathrm{C}$ for both Vero and Tango, while the breadth is significantly expanded to more than $60^{\circ} \mathrm{C}$ for the copolymer 2085. The rubbery modulus was determined as the storage modulus at $100^{\circ} \mathrm{C}$, where all polymers are in the rubbery state with negligible viscoelastic effects. As shown in Table 1, the corresponding rubbery modulus of the copolymer 2085 is about 4 times of Tango and 1/4 of Vero. The rubbery modulus $E_{\mathrm{r}}$ can be used to estimate the molecular weight $M_{\mathrm{c}}$ between crosslinks as $M_{\mathrm{c}}=3 \rho R T / E_{\mathrm{r}}$, where $\rho$ is the polymer density with a value of $1.17 \mathrm{~g} / \mathrm{cm}^{3}$ for three polymers and $R$ is the gas constant [39]. Based on the rubbery modulus, the molecular weight between the crosslinks can be calculated as 19100, 1220, and $4500 \mathrm{~g} / \mathrm{mol}$ for Tango, Vero, and the copolymer 2085. The crosslink density is proportional to $1 / M_{\mathrm{c}}$ and $E_{\mathrm{r}}$. Thus, the rubbery modulus can also provide the information of crosslink density.

Table 1. The mechanical properties of SMPs from the DMA tests.

\begin{tabular}{|l|c|c|c|c|}
\hline Material & $\begin{array}{c}\boldsymbol{T}_{\mathbf{g}}^{\mathbf{l}} \\
{\left[{ }^{\circ} \mathbf{C}\right]}\end{array}$ & $\begin{array}{c}\boldsymbol{T}_{\mathbf{g}}^{\mathbf{h}} \\
{\left[{ }^{\circ} \mathbf{C}\right]}\end{array}$ & $\begin{array}{c}\Delta \boldsymbol{T}_{\mathbf{g}} \\
{\left[{ }^{\circ} \mathbf{C}\right]}\end{array}$ & $\begin{array}{c}\boldsymbol{E}_{\mathbf{r}} \\
{[\mathbf{M P a}]}\end{array}$ \\
\hline Tango & -15.4 & 18.8 & 34.2 & 0.57 \\
\hline Vero & 40.0 & 70.0 & 30.0 & 8.90 \\
\hline 2085 & -3.7 & 59.0 & 62.7 & 2.40 \\
\hline
\end{tabular}

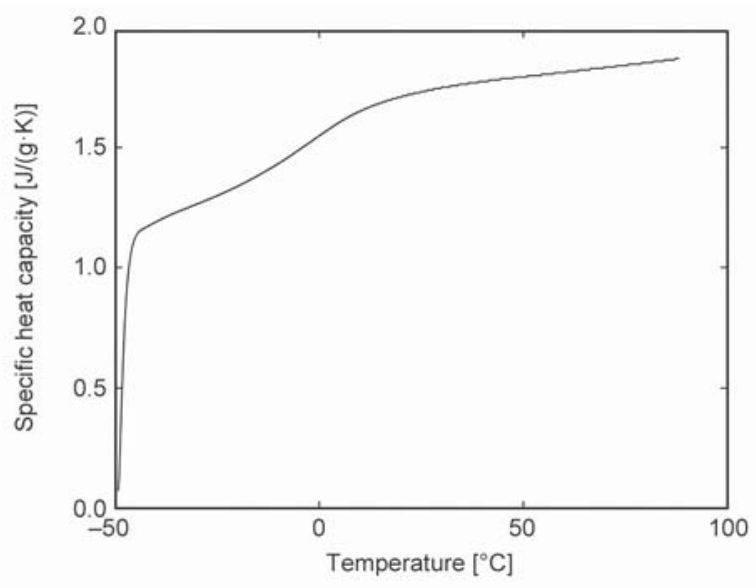

Figure 3. The DSC scanning of the copolymer 2085.

The copolymer exhibits a broad glass transition region. However, as shown in Figure 1b, the $\tan \delta$ curve is not smooth for the copolymer. It raises the question, whether it is possible that the copolymer exhibits a double $T_{\mathrm{g}}$ rather than a single broad glass transition behavior. Thus, we also perform a DSC scanning on the copolymer. Figure 3 shows that the copolymer exhibits a smooth glass transition behavior, which confirms that the copolymer exhibits a broad glass transition rather than a double $T_{\mathrm{g}}$.

To determine the loading force in the programming step of shape-memory tests, we have investigated the stress-strain relationships of three polymers with the results shown in Figure 4. The stress is calculated by dividing the applied force with the area of the initial cross-section. Thus, it is nominal stress or engineering stress. The strain is defined as the ratio between the displacement and the initial length of the specimen. It is also termed as the nominal strain or engineering strain. As shown, with increasing loading temperatures, the specimens become softer. For Tango, the response of specimens deformed at $40^{\circ} \mathrm{C}$ and $20^{\circ} \mathrm{C}$ almost overlap. This is also observed in the other two materials deformed at temperatures above $T_{\mathrm{g}}$. Vero exhibits a significantly larger stress response in the rubbery state, which indicates that Vero is a stiffer material. This result is consistent with the DMA results. We have also evaluated the failure strain of the three polymers. Tango is a ductile material. The uniaxial tension tests show that Tango can be stretched to more than $50 \%$ without failure. The failure strain of the copolymer 2085 is generally smaller than $20 \%$. Vero exhibits the smallest failure strain, ranging from $8-13 \%$. The measured failure strain was smaller than the data provided by the Stratasys. However, the general trend is the same. 

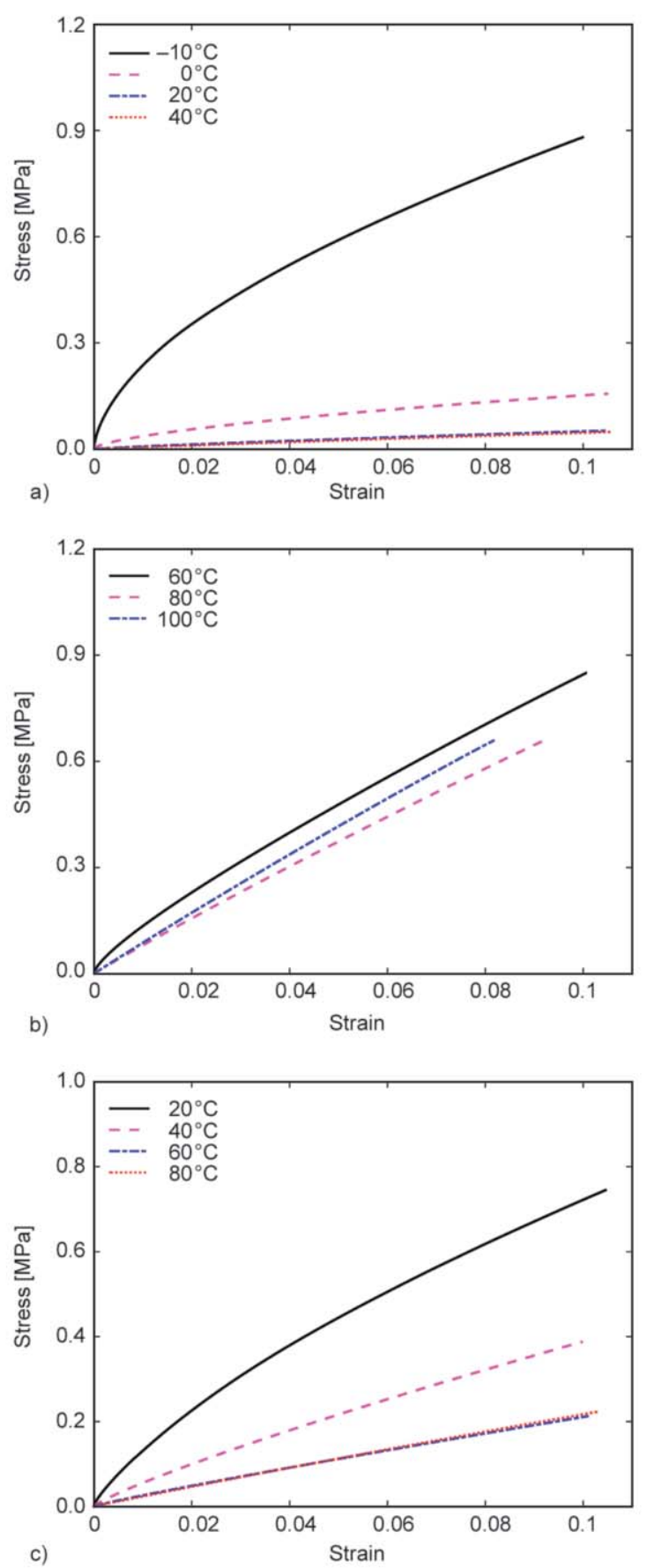

Figure 4. The stress-strain relationship at different temperatures for: (a) Tango, (b) Vero, and (c) copolymer 2085.

The dual-shape memory performances of three polymers are shown in Figure 5. The normalized strain is defined as $\bar{\varepsilon}=\left(\varepsilon-\varepsilon_{\min }\right) /\left(\varepsilon_{\max }-\varepsilon_{\min }\right)$, where $\varepsilon$ is the strain, and $\varepsilon_{\min }$ and $\varepsilon_{\max }$ are the corresponding minimum and maximum strains in the recovery process. For Tango and Vero, two different deformation temperatures were chosen. The shape recovery region only slightly shifts to a higher temperature

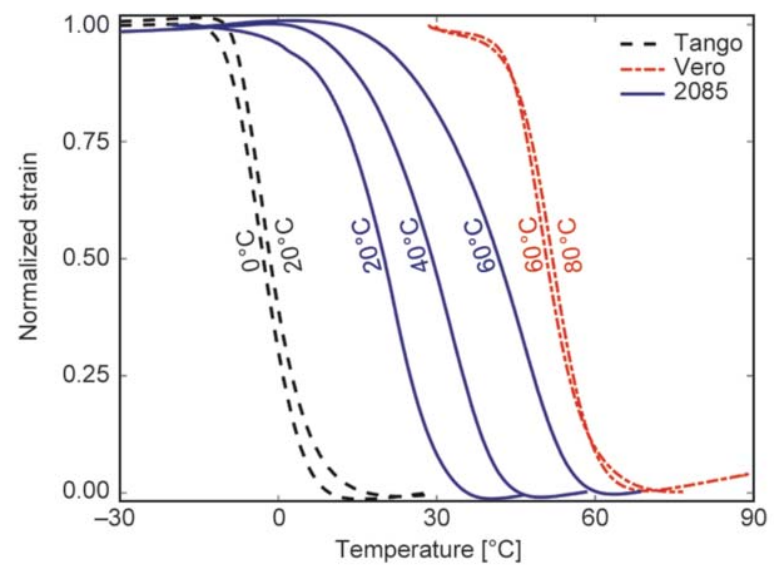

Figure 5. The dual-shape memory performance of three printed polymers.

region with increasing deformation temperatures. However, for the copolymer 2085, increasing the deformation temperature results in a pronounced increase in the recovery temperature, namely exhibiting a temperature memory effect. Figure 5 also clearly shows that the breadth of the recovery region of the copolymer 2085 is broader than that of Tango and Vero. The shape-fixity ratio and shape-recovery ratio were also analyzed. In all the conditions, the shape-fixity ratio is above $98 \%$, while the shape recovery ratio is around $90 \%$.

To further quantitatively evaluate the shape-memory performance, a similar method to that of determining the glass transition temperature is proposed to obtain the shape recovery temperature $T_{\mathrm{r}}^{\text {start }}$ and $T_{\mathrm{r}}^{\text {end }}$ (Figure 6). The fitted region was chosen as the first $5^{\circ} \mathrm{C}$ and the last $5^{\circ} \mathrm{C}$ of the recovery regions, as well as the regions with the normalized strain from $0.3-0.8$. The values of the recovery temperatures are listed in Table 2. Comparing the values listed in Tables 1 and 2 shows that the shape recovery region is within the glass transition region of each polymer. For the copolymer 2085, the shape recovery region at the deformation temperature $60^{\circ} \mathrm{C}$ is $25-57^{\circ} \mathrm{C}$, while that at the deformation temperature $20^{\circ} \mathrm{C}$ is from 9$31^{\circ} \mathrm{C}$. Only a small fraction of the recovery region overlaps between two cases, indicating that it is possible to achieve a triple-shape memory effect in this copolymer.

Among three polymers, Vero can withstand the smallest deformation. To obtain the information regarding how many cycles the materials can withstand, the cyclic test was performed on Vero. As shown in Figure 7, Vero still exhibits good shape-memory 


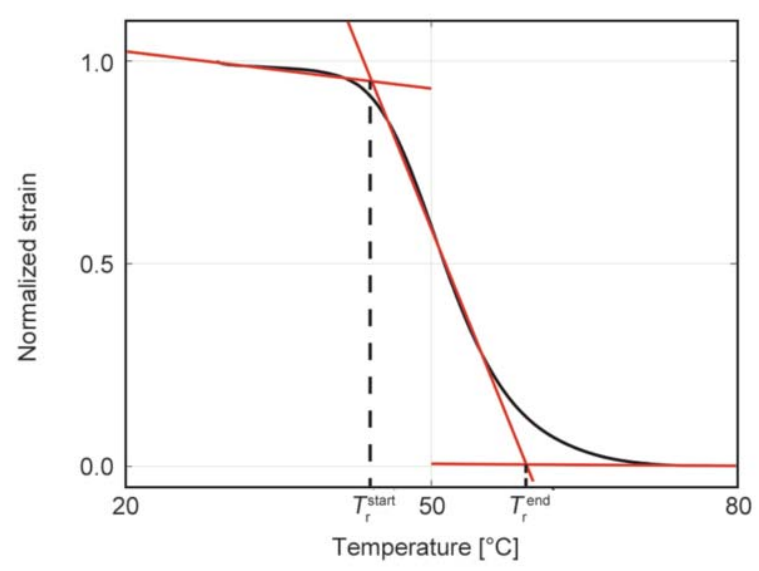

Figure 6. Determining the shape recovery region of dualshape memory tests.

performance after 10 cycles. This indicates that the printed SMPs can be repeatedly used for many cycles with similar shape-memory responses.

The triple-shape memory performance of the copolymer 2085 is illustrated in Figure 8. As shown, when unloaded at $20^{\circ} \mathrm{C}$, the programming strain decreases from 8.5 to $7.2 \%$, representing a shape-fixity ratio of $85 \%$ for the first temporary shape. A limited decrease in strain occurs after unloaded at $-20^{\circ} \mathrm{C}$ because the copolymer 2085 exhibits a stiff glassy response at this temperature. In the recovery process, when a holding process is allowed, the recovered shape shows a good correspondence to the unloaded shape. The strain at the final shape is not zero, indicating some permanent residual strain exists after the shapememory cycle. However, as shown in Figure 8a, without holding time, the two distinct temporary shapes cannot be well separated. This is because a broad glass transition region is employed to achieve the triple-shape memory effect. Thus, when heated to the intermediate temperature $\left(20^{\circ} \mathrm{C}\right)$, the second temporary shape has achieved shape recovery. However, with further increasing temperature, the first temporary shape already begins to recover. This is different from the method using two distinct transitions to

Table 2. The recovery temperature of the dual-shape memory performance.

\begin{tabular}{|l|c|c|c|c|}
\hline Material & $\begin{array}{c}\boldsymbol{T}_{\mathbf{p}} \\
{\left[{ }^{\circ} \mathbf{C}\right]}\end{array}$ & $\begin{array}{c}\boldsymbol{T}_{\mathbf{r}}^{\text {start }} \\
{\left[{ }^{\circ} \mathbf{C}\right]}\end{array}$ & $\begin{array}{c}\boldsymbol{T}_{\mathbf{r}}^{\text {end }} \\
{\left[{ }^{\circ} \mathbf{C}\right]}\end{array}$ & $\begin{array}{c}\Delta \boldsymbol{T}_{\mathbf{r}} \\
{\left[{ }^{\circ} \mathbf{C}\right]}\end{array}$ \\
\hline Tango & 0 & -10.0 & 4.8 & 14.8 \\
\hline Tango & 20 & -8.8 & 6.2 & 15.0 \\
\hline Vero & 60 & 43.4 & 59.1 & 15.7 \\
\hline Vero & 80 & 44.0 & 60.2 & 16.2 \\
\hline 2085 & 20 & 9.4 & 31.2 & 21.8 \\
\hline 2085 & 40 & 16.0 & 42.6 & 26.6 \\
\hline 2085 & 60 & 25.5 & 57.1 & 31.6 \\
\hline
\end{tabular}
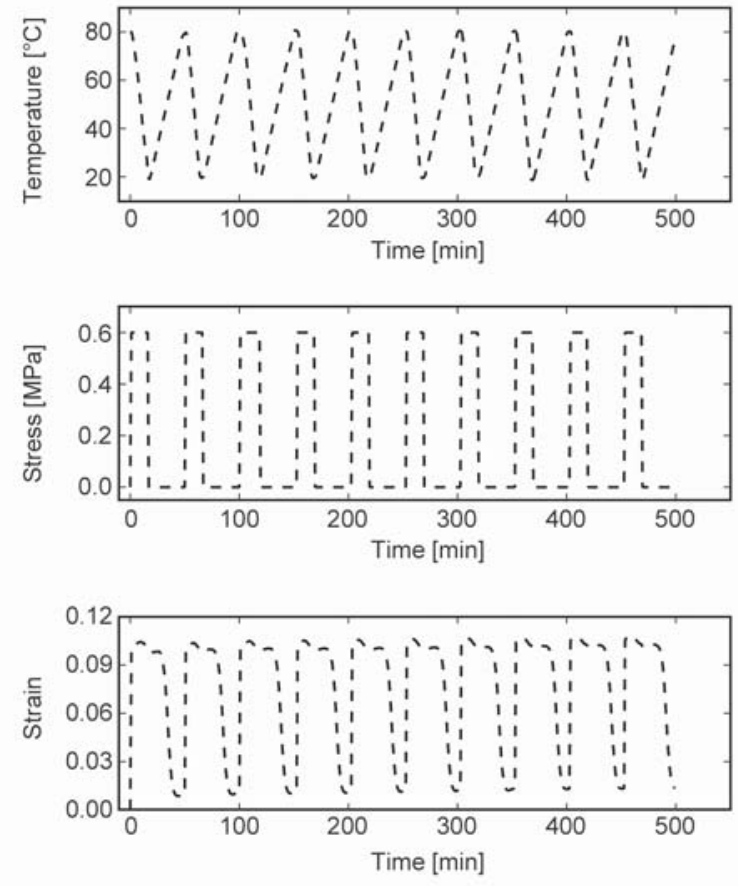

Figure 7. The cyclic shape-memory performance of Vero.

achieve triple-shape memory effect. If the two transition regions are well separated, the recovery of two temporary shapes can also be separated. Overall, the shape fixity ratio for the first temporary shape is $85 \%$, and that for the second temporary shape is above $99 \%$. The shape recovery ratio for the second temporary shape is $95 \%$, while the shape recovery ratio for the first recovery ratio is $90 \%$. However, the maximum applied strain chosen is only around $12 \%$, which is a small value compared with SMPs in the literature. In the preliminary study, we found that with further increasing the applied loading, the specimens can fail during the shape-memory cycle.

While the above tests have shown the shape-memory performances of the printed polymers in uniaxial deformation conditions, it is intriguing to demonstrate the abilities of the printed polymers to be programmed with complex temporary shapes. Here we first show that a film specimen of the copolymer 2085 can be programmed to different 3D shapes. As shown in Figure 9, two different sets of temporary shapes were designed. For the first set, the film specimen was first programmed with a wave shape and then deformed to a ' $\infty$ ' shape. During the recovery process, the specimen first returned to the wave shape and then to the permanent rectangular shape. We also noticed that the recovered shape at $20^{\circ} \mathrm{C}$ was not exactly the same as the unloaded first temporary shape. It seemed that a certain ratio of the first temporary shape already recovered when holding at $20^{\circ} \mathrm{C}$. The 

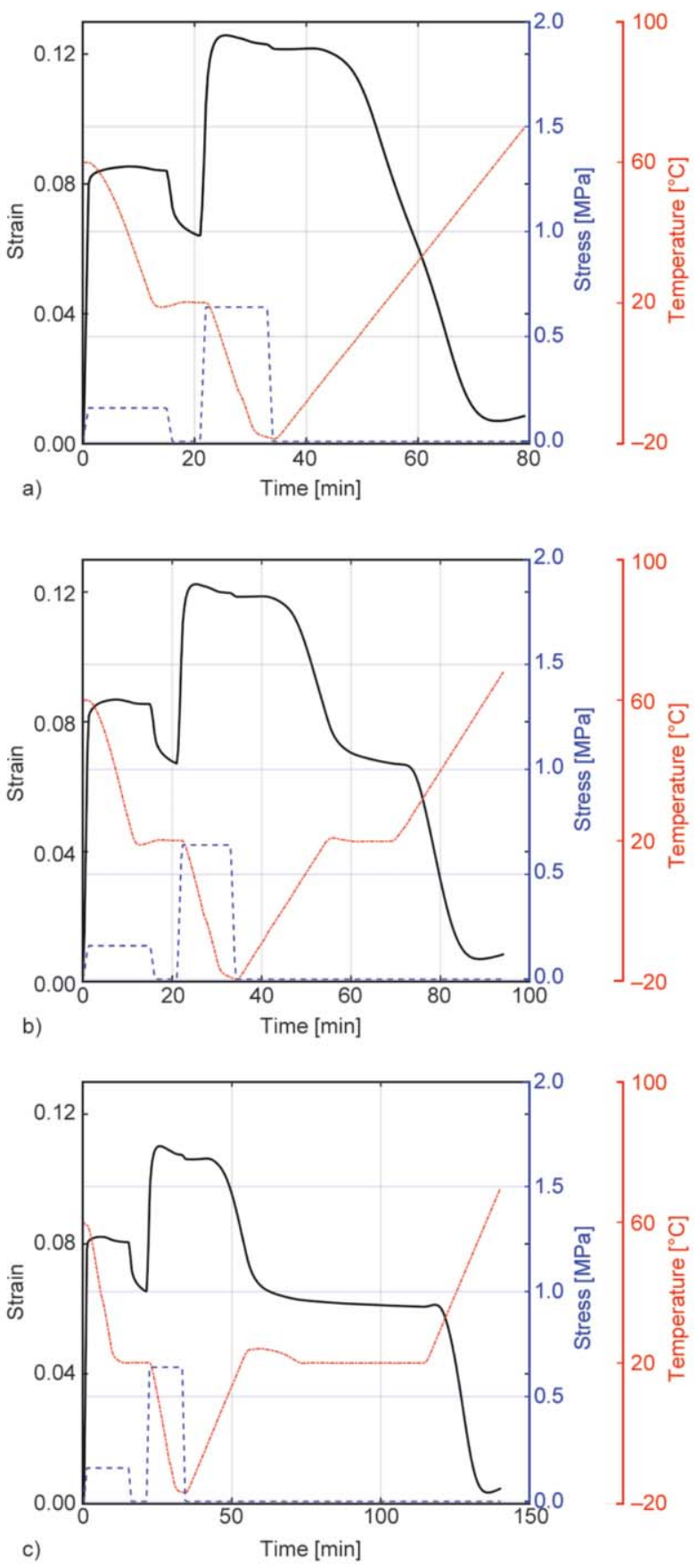

Figure 8. A triple-shape memory cycle for the copolymer 2085 with varied holding time at the intermediate temperature $20^{\circ} \mathrm{C}$ : (a) $0 \mathrm{~min}$, (b) $15 \mathrm{~min}$, and (c) $60 \mathrm{~min}$.

copolymer exhibits a better triple-shape memory effect in a uniaxial mode, as shown in Figure 8. However, for the complex programming conditions, as shown in Figure 9a, the copolymer may lose some shape fixity of the first programmed temporary shape. This is probably because the programmed strain is small in the bending/twisting condition though the geometric shape change is large. The shape fixity and recovery may depend on the amount of the programed

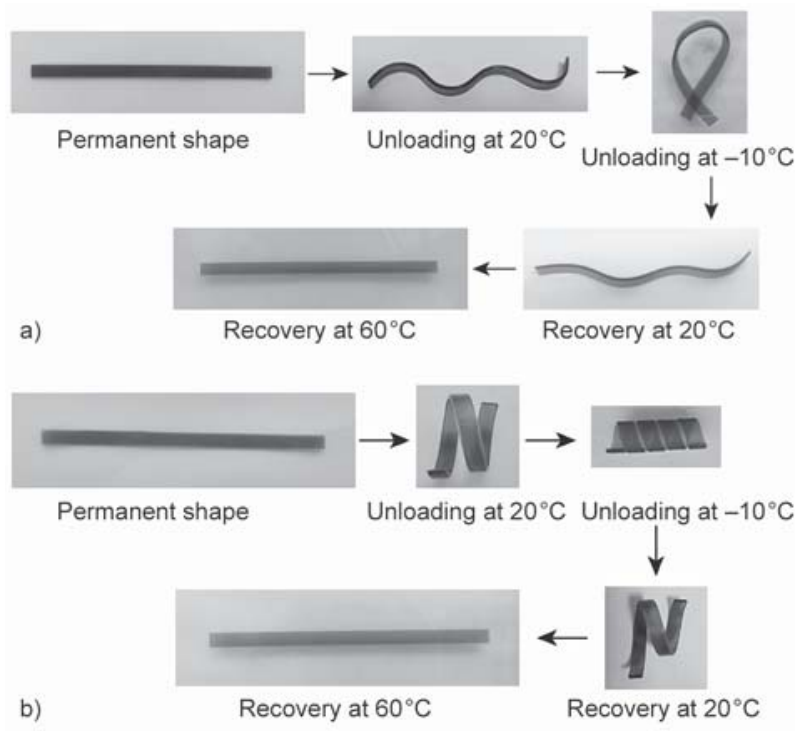

Figure 9. Demonstration of triple-shape memory effect in the copolymer 2085 with different temporary shapes: (a) a wave shape and a ' $\infty$ ' shape, and (b) two helical shapes.

strain. For the second set, the two temporary shapes were both set as helix shapes with different diameters. As shown, the copolymer can achieve a subsequent recovery from the helix shape with a small diameter to the helix shape with a large diameter, and eventually to the original shape. The results also show that the recovery process at $20^{\circ} \mathrm{C}$ takes less than $1 \mathrm{~min}$. The recovered shape was stable with no apparent change when held for $10 \mathrm{~min}$ at $20^{\circ} \mathrm{C}$. This is consistent with the results of Figure $8 \mathrm{~b}$ and $8 \mathrm{c}$.

The $3 \mathrm{D}$ printing technique also allows us to create complex structures with multiple materials. Here, we printed a planar structure composed of the stiff polymer Vero and the copolymer 2085. The planar structure can be folded to a box with the hinge part composed of the copolymer 2085. The shape-memory cycle is demonstrated in Figure 10. Figure 11 shows the two temporary shapes after unloading and the recovery shapes at 20 and $60^{\circ} \mathrm{C}$, respectively. From this demonstration, we can also estimate the shape fixity ratio and shape recovery ratio. Here we used the bending angle as the parameter similar to the strain. The initial folding angle was $90^{\circ}$. The angle after unloading at $20^{\circ} \mathrm{C}$ was $68^{\circ}$. The angle of the second temporary shape was set as $0^{\circ}$ and the angle changes negligibly after unloading. The recovery angle at $20^{\circ} \mathrm{C}$ was measured as $56^{\circ}$. Thus, the shape fixity ratio for the first and second temporary shape can be approximated as $75 \%$ and nearly $100 \%$, while the shape recovery ratio for the first and second temporary shape 


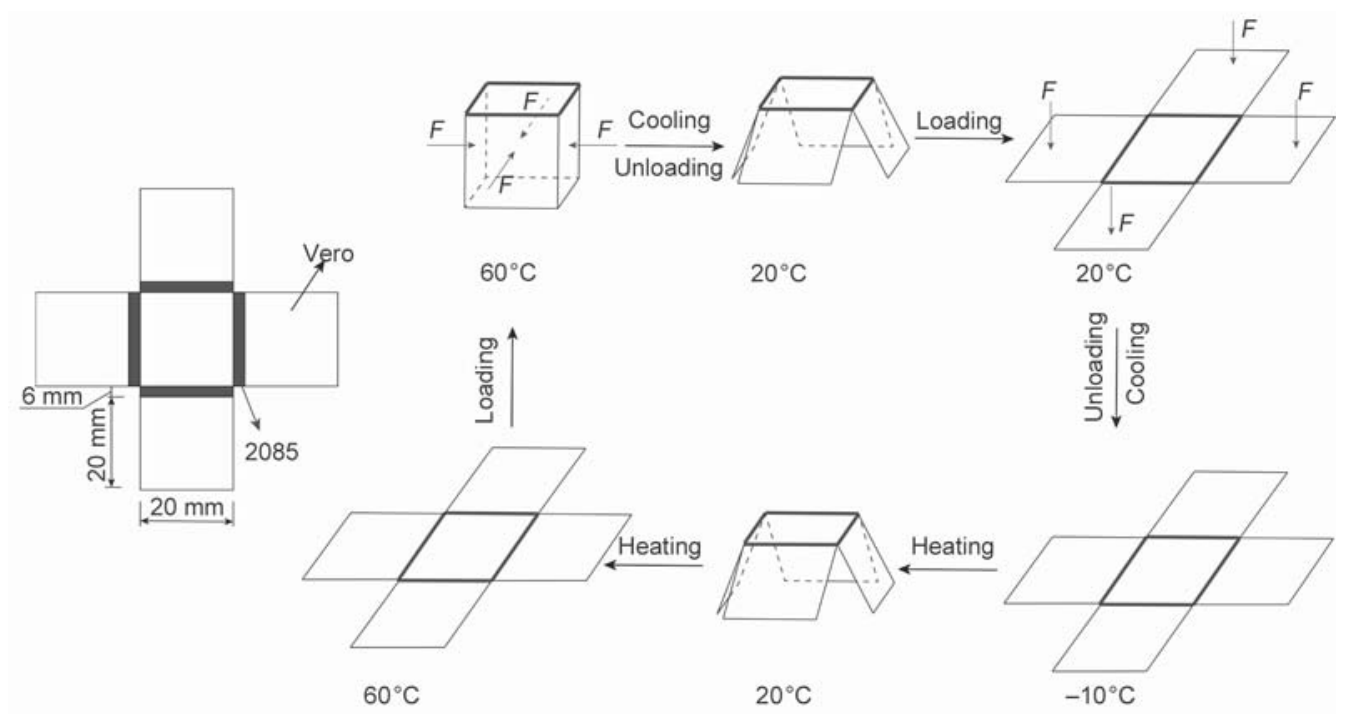

Figure 10. A schematic diagram of 3D triple-shape memory effect of the structure composed of Vero and copolymer 2085.

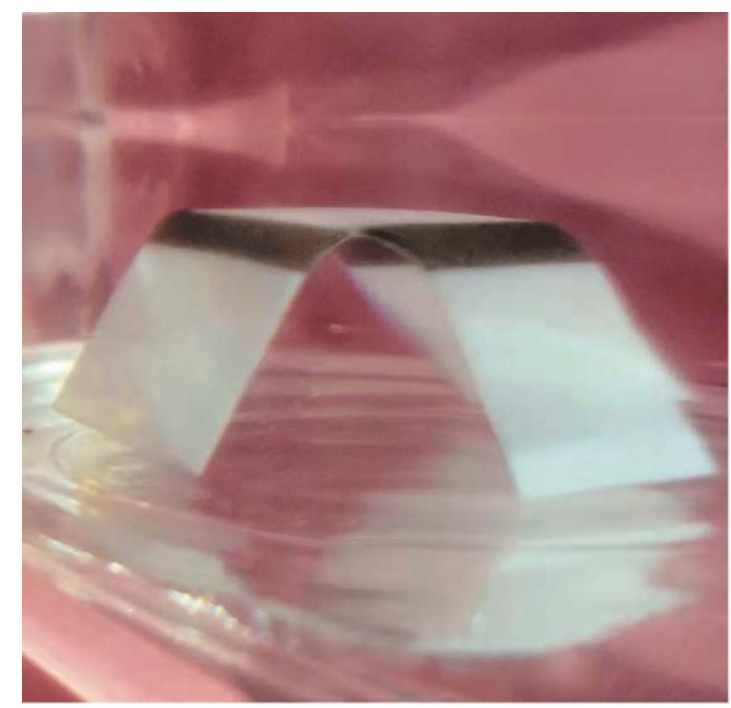

Unloading at $20^{\circ} \mathrm{C}$

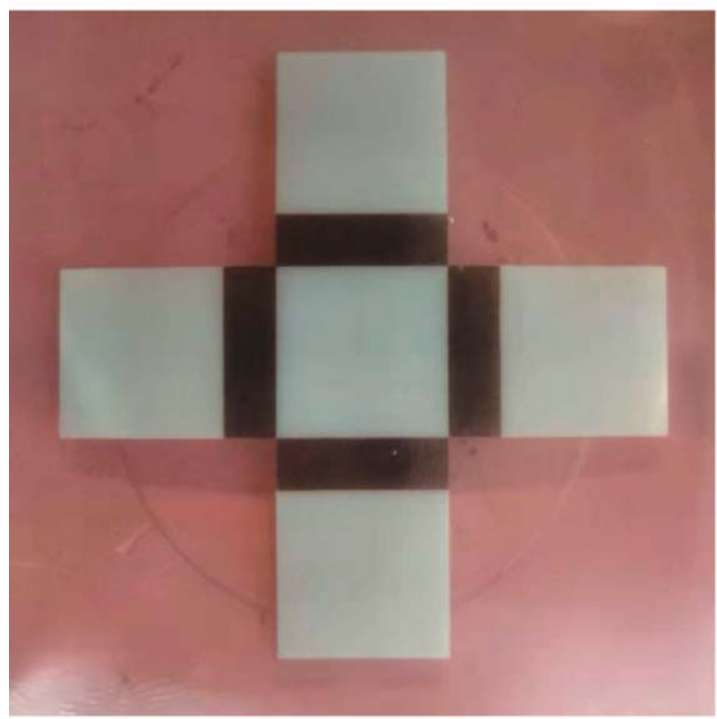

Recovery at $60^{\circ} \mathrm{C}$

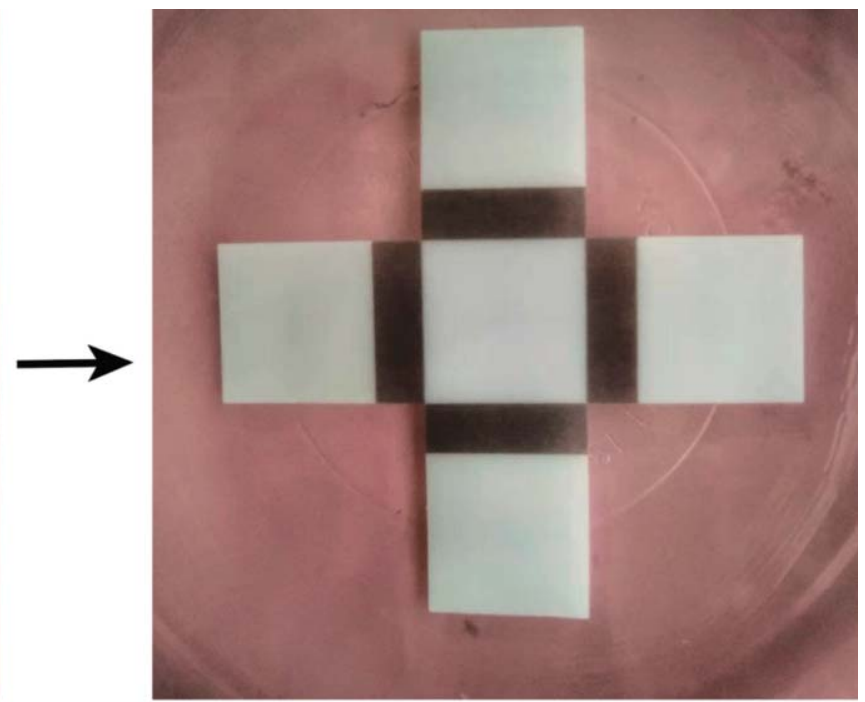

Unloading at $-10^{\circ} \mathrm{C}$
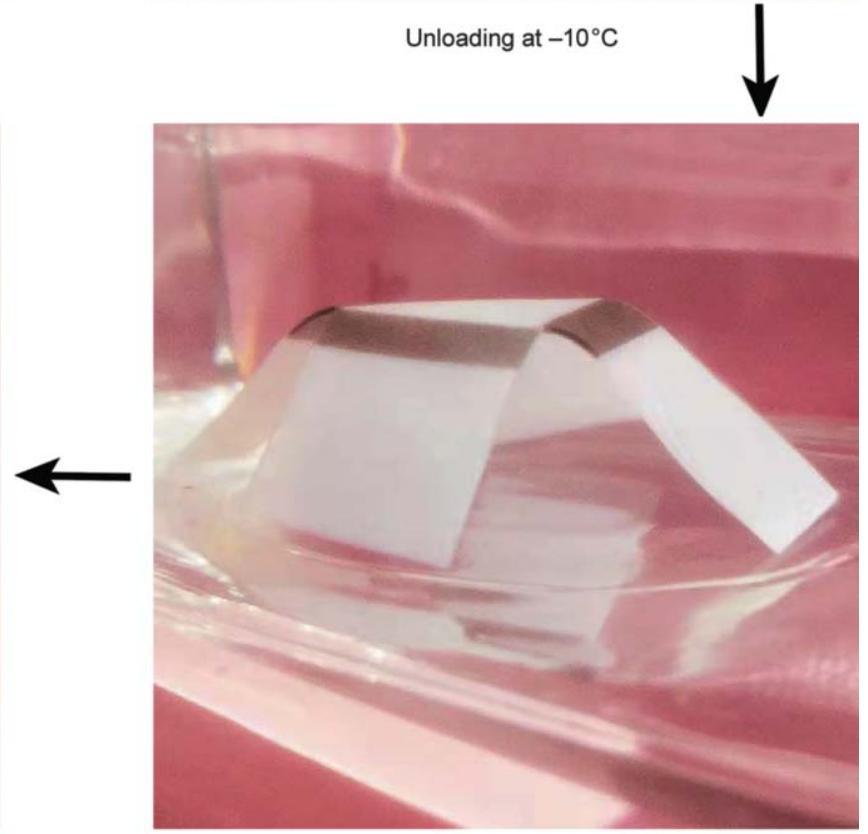

Recovery at $20^{\circ} \mathrm{C}$

Figure 11. Three-dimensional demonstration of the triple-shape memory performance of the structure composed of Vero and copolymer 2085. 
can be approximated as $82 \%$ and nearly $100 \%$. This demonstration confirms a good triple-shape memory performance of the copolymer 2085 and provides inspiration for designing various kinds of deployable models using printed structures based on SMPs.

\section{Conclusions}

In this work, we investigate the shape-memory performance of three printed polymers. Each pure polymer exhibits a narrow yet well-separated glass transition region. In contrast, the copolymer 2085 has a much broader glass transition region spanning more than $60^{\circ} \mathrm{C}$. In the dual-shape memory performance, both Vero and Tango are insensitive to deformation temperatures, while the copolymer 2085 shows a clear temperature memory effect. The copolymer demonstrates a good triple-shape memory performance. The main contribution of this work is that we demonstrate that the commercial printed 3D polymers can exhibit a good triple-shape memory response. Thus, structures with complex geometry can be readily designed and applied for practical applications. However, the failure strain of the printed SMPs is within the median strain region, which limits the application requiring a large deformation strain. We also want to emphasize that large scale geometrical shape changes still can be achieved by using these materials when deformed in bending or twisting modes, in which the extensional strain is low.

\section{Acknowledgements}

R. Xiao acknowledges the funding support from the National Natural Science Foundation of China (Grant No. 11828201).

\section{References}

[1] Lendlein A., Kelch S.: Shape-memory polymers. Angewandte Chemie International Edition, 41, 2034-2057 (2002). https://doi.org/10.1002/15213773(20020617)41:12<2034::AID-ANIE2034>3.0.CO;2-M

[2] Wang Z., Li W., Yang X., Cao J., Tu Y., Wu R., Wang W.: Highly stretchable and compressible shape memory hydrogels based on polyurethane network and supramolecular interaction. Materials Today Communications, 17, 246-251 (2018).

https://doi.org/10.1016/j.mtcomm.2018.09.006

[3] Lin L., Zhou Q., Li M.: A thermally and electrically shape memory polymer prepared by a novel electromixed fusion preparation method. Materials Letters, 256, 126574/1-126574/5 (2019).

https://doi.org/10.1016/j.matlet.2019.126574
[4] Li J., Kan Q., Chen K., Liang Z., Kang G.: In situ observation on rate-dependent strain localization of thermo-induced shape memory polyurethane. Polymers, 11, 982/1-982/17 (2019). https://doi.org/10.3390/polym11060982

[5] Patel K. K., Purohit R.: Improved shape memory and mechanical properties of microwave-induced shape memory polymer/MWCNTs composites. Materials Today Communications, 20, 100579/1-100579/8 (2019). https://doi.org/10.1016/j.mtcomm.2019.100579

[6] Liu R., Li Y., Liu Z.: Experimental study of thermo-mechanical behavior of a thermosetting shape-memory polymer. Mechanics of Time-Dependent Materials, 23, 249-266 (2019). https://doi.org/10.1007/s11043-018-9377-0

[7] Luo X., Mather P. T.: Triple-shape polymeric composites (TSPCs). Advanced Functional Materials, 20, 2649 2656 (2010).

https://doi.org/10.1002/adfm.201000052

[8] Xie T., Page K. A., Eastman S. A.: Strain-based temperature memory effect for nafion and its molecular origins. Advanced Functional Materials, 21, 2057-2066 (2011). https://doi.org/10.1002/adfm.201002579

[9] Wang X., Lu H., Shi X., Yu K., Fu Y. Q.: A thermomechanical model of multi-shape memory effect for amorphous polymer with tunable segment compositions. Composites Part B: Engineering, 160, 298-305 (2019). https://doi.org/10.1016/j.compositesb.2018.10.048

[10] Du H., Liu L., Zhang F., Leng J., Liu Y.: Triple-shape memory effect in a styrene-based shape memory polymer: Characterization, theory and application. Composites Part B: Engineering, 173, 106905/1-106905/10 (2019).

https://doi.org/10.1016/j.compositesb.2019.106905

[11] Gu L., Jiang Y., Hu J.: Bioinspired poly(vinyl alcohol)silk hybrids: Two-way water-sensitive shape-memory materials. Materials Today Communications, 17, 419426 (2018). https://doi.org/10.1016/j.mtcomm.2018.10.005

[12] Sun L., Wang T. X., Chen H. M., Salvekar A. V., Naveen B. S., Xu Q., Weng Y., Guo X., Chen Y., Huang W. M.: A brief review of the shape memory phenomena in polymers and their typical sensor applications. Polymers, 11, 1049/1-1049/35 (2019).

https://doi.org/10.3390/polym11061049

[13] Chen G., Zhang Q., Lu M., Liu Y., Wang S., Wu K., Lu M.: A triple-shape memory material via thermal responsive behavior of liquid crystalline network incorporating main-chain/side-chain LC units. Macromolecular Chemistry and Physics, 220, 1900059/1-1900059/10 (2019).

https://doi.org/10.1002/macp.201900059

[14] Hoeher R., Raidt T., Krumm C., Meuris M., Katzenberg F., Tiller J. C.: Tunable multiple-shape memory polyethylene blends. Macromolecular Chemistry and Physics, 214, 2725-2732 (2013). https://doi.org/10.1002/macp.201300413 
[15] Hoeher R., Raidt T., Katzenberg F., Tiller J. C.: Heating rate sensitive multi-shape memory polypropylene: A predictive material. ACS Applied Materials and Interfaces, 8, 13684-13687 (2016).

https://doi.org/10.1021/acsami.6b04177

[16] Ji S., Wang J., Olah A., Baer E.: Triple-shape-memory polymer films created by forced-assembly multilayer coextrusion. Journal of Applied Polymer Science, 134, 44405/1-44405/10 (2017).

https://doi.org/10.1002/app.44405

[17] Ji X., Chen D., Zheng Y., Shen J., Guo S., Harkin-Jones E.: Multilayered assembly of poly(vinylidene fluoride) and poly(methyl methacrylate) for achieving multishape memory effects. Chemical Engineering Journal, 362, 190-198 (2019)

https://doi.org/10.1016/j.cej.2019.01.016

[18] Molavi F. K., Ghasemi I., Messori M., Esfandeh M.: Nanocomposites based on poly(L-lactide)/poly( $\varepsilon$-caprolactone) blends with triple-shape memory behavior: Effect of the incorporation of graphene nanoplatelets (GNps). Composites Science and Technology, 151, 219-227 (2017).

https://doi.org/10.1016/j.compscitech.2017.08.021

[19] Yang K., Du J., Zhang Z., Ren T.: A facile strategy to fabricate robust triple-shape memory polymer. Materials Letters, 257, 126753/1-126753/3 (2019).

https://doi.org/10.1016/j.matlet.2019.126753

[20] Molavi F. K., Ghasemi I., Messori M., Esfandeh M.: Design and characterization of novel potentially biodegradable triple-shape memory polymers based on immiscible poly(L-lactide)/poly( $\varepsilon$-caprolactone) blends. Journal of Polymers and the Environment, 27, 632-642 (2019).

https://doi.org/10.1007/s10924-019-01366-6

[21] Li M., Guan Q., Dingemans T. J.: High-temperature shape memory behavior of semicrystalline polyamide thermosets. ACS Applied Materials and Interfaces, 10, 19106-19115 (2018).

https://doi.org/10.1021/acsami.8b03658

[22] Jia Y., Ying H., Zhang Y., He H., Cheng J.: Reconfigurable poly(urea-urethane) thermoset based on hindered urea bonds with triple-shape-memory performance. Macromolecular Chemistry and Physics, 220, 1900148/1-1900148/7 (2019). https://doi.org/10.1002/macp.201900148

[23] Xie T.: Tunable polymer multi-shape memory effect. Nature, 464, 267-270 (2010). https://doi.org/10.1038/nature08863

[24] Xiao R., Zhang C., Huang W. M.: Programming of shape-memory polymers: The temperature memory effect and triple/multiple-shape-memory effect in polymers. in 'Shape-memory polymer device design' (eds.: Safranski D. L., Griffis J. C.) William Andrew Publishing, Cambridge, 113-137 (2017).

https://doi.org/10.1016/B978-0-323-37797-3.00004-X
[25] Wang K., Jia Y-G., Zhao C., Zhu X. X.: Multiple and two-way reversible shape memory polymers: Design strategies and applications. Progress in Materials Science, 105, 100572/1-100572/39 (2019).

https://doi.org/10.1016/j.pmatsci.2019.100572

[26] Yu K., Dunn M. L., Qi H. J.: Digital manufacture of shape changing components. Extreme Mechanics Letters, 4, 9-17 (2015). https://doi.org/10.1016/j.eml.2015.07.005

[27] Chen S., Zhang Q., Feng J.: 3D printing of tunable shape memory polymer blends. Journal of Materials Chemistry C, 5, 8361-8365 (2017). https://doi.org/10.1039/C7TC02534C

[28] Li A., Challapalli A., Li G.: 4D Printing of recyclable lightweight architectures using high recovery stress shape memory polymer. Scientific Reports, 9, 7621/17621/13 (2019). https://doi.org/10.1038/s41598-019-44110-9

[29] Zhang B., Zhang W., Zhang Z., Zhang Y-F., Hingorani H., Liu Z., Liu J., Ge Q.: Self-healing four-dimensional printing with an ultraviolet curable double-network shape memory polymer system. ACS Applied Materials and Interfaces, 11, 10328-10336 (2019).

https://doi.org/10.1021/acsami.9b00359

[30] Lin C., Lv J., Li Y., Zhang F., Li J., Liu Y., Liu L., Leng J.: 4D-printed biodegradable and remotely controllable shape memory occlusion devices. Advanced Functional Materials, 29, 1906569/1-1906569/10 (2019).

https://doi.org/10.1002/adfm.201906569

[31] Shie M-Y., Shen Y-F., Astuti S. D., Lee A. K-X., Lin S-H., Dwijaksara N. L., Chen Y-W.: Review of polymeric materials in $4 \mathrm{D}$ printing biomedical applications. Polymers, 11, 1864/1-1864/17 (2019). https://doi.org/10.3390/polym11111864

[32] Wan X., Wei H., Zhang F., Liu Y., Leng J.: 3D printing of shape memory poly(D,L-lactide-co-trimethylene carbonate) by direct ink writing for shape-changing structures. Journal of Applied Polymer Science, 136, 48177/1-48177/12 (2019).

https://doi.org/10.1002/app.48177

[33] Miao J-T., Ge M., Peng S., Zhong J., Li Y., Weng Z., Wu L., Zheng L.: Dynamic imine bond-based shape memory polymers with permanent shape reconfigurability for 4D printing. ACS Applied Materials and Interfaces, 11, 40642-40651 (2019).

https://doi.org/10.1021/acsami.9b14145

[34] Peng B., Yang Y., Gu K., Amis E. J., Cavicchi K. A.: Digital light processing 3D printing of triple shape memory polymer for sequential shape shifting. ACS Materials Letters, 1, 410-417 (2019).

https://doi.org/10.1021/acsmaterialslett.9b00262

[35] Inverardi N., Pandini S., Bignotti F., Scalet G., Marconi S., Auricchio F.: Sequential motion of 4D printed photopolymers with broad glass transition. Macromolecular Materials and Engineering, 305, 1900370/11900370/11 (2020).

https://doi.org/10.1002/mame.201900370 
[36] Bodaghi M., Damanpack A. R., Liao W. H.: Triple shape memory polymers by $4 \mathrm{D}$ printing. Smart Materials and Structures, 27, 065010/1-065010/16 (2018). https://doi.org/10.1088/1361-665X/aabc2a

[37] Lee A. Y., An J., Chua C. K., Zhang Y.: Preliminary investigation of the reversible $4 \mathrm{D}$ printing of a dual-layer component. Engineering, 5, 1159-1170 (2019).

https://doi.org/10.1016/j.eng.2019.09.007
[38] Yuan C., Wang F., Qi B., Ding Z., Rosen D. W., Ge Q.: 3D printing of multi-material composites with tunable shape memory behavior. Materials and Design, in press (2020).

https://doi.org/10.1016/j.matdes.2020.108785

[39] Yakacki C. M., Nguyen T. D., Likos R., Lamell R., Guigou D., Gall K.: Impact of shape-memory programming on mechanically-driven recovery in polymers. Polymer, 52, 4947-4954 (2011).

https://doi.org/10.1016/j.polymer.2011.08.027 